\title{
Gender Disparity in Academic Neurosurgery
}

Tiffany Odell ${ }^{1}$, Harjyot Toor ${ }^{2}$, Ariel Takayanagi ${ }^{2}$, Bailey Zampella ${ }^{2}$, Javed Siddiqi ${ }^{1}$, Sabeena Jalal ${ }^{3}$, Khashayar Golbaz $^{3}$, Sadia Qamar ${ }^{4}$, Faisal Khosa ${ }^{3}$

1. Neurosurgery, Desert Regional Medical Center, Palm Springs, USA 2. Neurosurgery, Riverside University Health System Medical Center, Moreno Valley, USA 3. Radiology, Vancouver General Hospital, Vancouver, CAN 4. Radiology, University of British Columbia, Vancouver, CAN

$\square$ Corresponding author: Harjyot Toor, harjyot.toor@tu.edu

Disclosures can be found in Additional Information at the end of the article

\section{Abstract}

\section{Background}

In the 1960 s, less than $10 \%$ of medical school graduates were women. Today, almost half of all medical school graduates are women. Despite the significant rise in female medical school graduates, there continues to be a large gender gap in most subspecialties, particularly surgical subspecialties such as neurosurgery.

\section{Objective}

The purpose of our study was to assess the factors contributing to differences in the academic ranks of male and female staff in academic neurosurgery programs in Canada and the United States (US).

\section{Methods}

Data about women in academic neurosurgery was collected from a number of sources, including Fellowship and Residency Electronic Interactive Database (FREIDA), Accreditation Council for Graduate Medical Education (ACGME), Canadian Resident Matching Service (CaRMS) FRIEDA, ACGME, CaRMS, Pubmed, and Scopus, to create a database of all neurosurgeons in the US and Canada. The analysis included neurosurgeons in academic and leadership ranks and also the $\mathrm{H}$ index, citations, publications, citations per year, and publications per year.

\section{Results}

Women represent only $12 \%$ of neurosurgeons in the US and Canada. When gender is further analyzed by academic appointment, women represent just over $12 \%$ of neurosurgeons at the assistant and associate professor levels (15.44\% and $13.27 \%$, respectively) but significantly less at the full professor level (5.84\%). Likewise, only $7.45 \%$ of women hold first-in command

Received 03/13/2019

Review began 04/22/2019 Review ended 05/01/2019 Published 05/09/2019

(c) Copyright 2019

Odell et al. This is an open access article distributed under the terms of the Creative Commons Attribution License CC-BY 3.0., which permits unrestricted use, distribution, and reproduction in any medium, provided the original author and source are credited. leadership positions while $4.69 \%$ hold second-in-command positions within their institutions.

\section{Conclusions}

The existing data shows that women are significantly under-represented in academic neurosurgery. Lack of role models, experience, limited scientific output, and aspirations of a controlled lifestyle could be the potential contributing factors.

Categories: Medical Education, Quality Improvement, Healthcare Technology

Keywords: gender disparity, h-index, publications, research productivity, women in neurosurgery, 


\section{Introduction}

In recent years, women have surpassed their male counterparts on the education forefront, earning more undergraduate degrees than men. Women now pursue graduate-level education in all fields and, reflectively, medical school enrollment has experienced an increasing number of female applicants. In the 2015-2016 academic year, $46.4 \%$ of medical school graduates were women [1]. This is a considerable change from 1965 when women accounted for $9 \%$ of the United States (US) medical school enrollees and a meager 7\% of medical school graduates [2]. Despite the numbers showing that women now represent about $50 \%$ of all medical school enrollees, women are still underrepresented in the profession, particularly in subspecialties such as anesthesiology, infectious disease, oncology, and radiology [3-6]. A study published in 2017 concluded that male North American musculoskeletal radiologists significantly outnumber their female colleagues, who are also underrepresented in professorship roles and have lower odds of attaining a high h-index score, a metric that attempts to measure both the productivity and citation impact of the publications of a scientist or scholar [4]. Another study published in the same year reported significant gender disparity in leadership among neuroradiologists [5]. Almost half of all North American dermatologists are noted to be women, yet only a quarter occupy faculty positions [7]. Women are also found to be less productive than male dermatologists in research in terms of years spent in research, the number of publications, and citations [7]. Women were shown to lag behind men in research productivity even in the field of breast imaging where they dominate [8]. The only subspecialties in which women comprise a higher percentage than men were Child and Adolescent Psychiatry, Geriatric Medicine, Pediatrics, and Obstetrics and Gynecology [9]. In particular, surgical subspecialties have the most significant gender gap. In the US, a reported $14 \%$ of women choose to go into a surgical subspecialty as compared to $33 \%$ of men [10]. Of the surgical subspecialties, this is most pronounced in Orthopedic and Thoracic surgery where women account for only $5 \%$ and $6 \%$, respectively [9]. 2015 data from the U.S. show that women make up $7.8 \%$ of neurosurgeons [9]. In this study, we examine female neurosurgeons in the United States and Canada according to their academic title, participation in leadership, and research productivity.

\section{Materials And Methods}

The database for the academic and administrative faculty members for neurosurgery programs, across the US and Canada, was created between January to May of 2017. For US programs, the official website of Fellowship and Residency Electronic Interactive Database (FREIDA) was used as the primary resource. This database provides information about all the neurosurgery residency programs accredited by the Accreditation Council for Graduate Medical Education (ACGME) enrolled with the American Medical Association (AMA). A total of 110 neurosurgery programs listed in FREIDA online were searched for faculty listing. Out of these 110 programs, faculty listing was available for only 100 programs. Ten programs were excluded from the data collection, as the required faculty information was not available on the program's official website. Canadian Resident Matching Service (CaRMS), a national, independent organization, provides discipline and university-based enlisting of residency program descriptions in Canada. The official webpage of CaRMS was utilized as the principal source for identifying the neurosurgery programs available in Canada, by discipline and university-based search criteria. Nine enlisted programs were searched for faculty listing. Final inclusion criteria were based on the availability of faculty listing on the official webpage of the both the US and Canadian neurosurgery programs.

Faculty listings of the division of neurosurgery, from the respective websites of the selected universities, were reviewed. The faculty listings were searched for gender, academic ranking, and departmental leadership roles. The members whose gender could not be identified from the 
university website were further searched utilizing their Doximity (Doximity, Inc., San Francisco, California) and LinkedIn (LinkedIn Corporation, Mountain View, California) profiles. Only the members with the academic ranking of Professor, Associate Professor and Assistant Professor with MD degrees were included. Members without these academic rankings were excluded. Adjunct and retired faculty were also excluded from the final data set. Physicians were further categorized for their departmental leadership roles, including Chief, Co-Chief, Section Chief, Director, Co-Director, Section Director, Program Director, Chair, Vice-Chair, Head, and Section-Head. Elsevier's Scopus (Elsevier, New York, US), the largest abstract and citation database for peer-reviewed literature was used to collect information about the publications, h-index, citations, and duration of the research in years for each faculty member. The average number of publications and citations per active research year for each faculty member was also calculated.

Scopus was chosen because of its reliability and consistency in measuring the h-index when compared to Google Scholar (Google, Mountain View, California) and Web of Science. Scopus has 40 million publications recorded and is the most reliable tool for calculating the h-index because of its excellence at distinguishing authors. A published study shows a high degree of correlation between $\mathrm{H}$-indices calculated from Google Scholar and Scopus. The h-index is defined as an author-level metric that measures both the productivity and citation impact of the publications of a scientist or scholar. This is based on the set of the scientist's most-cited papers and the number of citations that they have received in other publications.

Once data was obtained, the analysis was carried out using Stata software (version 14.2, StataCorp LLC, College Station, Texas). Data were tested for normality using the KolmogorovSmirnov test and histograms. Since the distribution was skewed, median and ranges were calculated for quantitative variables. Frequency and percentages were calculated for qualitative variables. Chi-square was applied to see the difference between gender and academic ranks and gender and leadership ranks, applying a $\mathrm{p}$-value of $\leqslant 0.05$ as statistically significant. The MannWhitney $\mathrm{U}$ test was used to observe the difference between males and females for the h-index, citations, publications, citations/year, and publications/year. The Kruskal-Wallis test was used to see the difference between academic ranks and leadership ranks for the h-index, citations, publications, citations per year, and publications per year. A multiple linear regression analysis was applied since the h-index was the outcome of interest and gender was the main exposure.

\section{Results}

Looking at leadership ranks, we saw that 319 faculty were serving in different leadership positions. A total of 236 men (92.55\%) were in first-in-command leadership positions, 19 females (7.45\%) were working in first-in-command positions, 61 males (95.31\%) were working in second-in-command positions, and three females (4.69\%) were working in second-incommand positions, as seen in Figure 1. A total of 1811 neurosurgery faculty members in the US and Canada were identified. Of those, 1592 (87.91\%) were males, and 219 (12.09\%) were females. Among the 1811 neurosurgery faculty identified, 842 (46.49\%) were Assistant Professors, 437 (24.13\%) were Associate Professors, and 532 (29.38\%) were Professors. Women held proportionately more Assistant and Associate Professorships as compared to their overall faculty male:female ratios, however, they held significantly less full Professor positions; only 5.84\% as compared to $94.16 \%$ male counterparts, as noted in Figure 2. Looking at leadership ranks, we saw that 319 faculty were serving in different leadership positions; 236 men (92.55\%) were in first-in-command leadership positions, 19 females (7.45\%) were working in first-incommand positions, 61 males (95.31\%) were working in second-in-command positions, and three females (4.69\%) were working in second-in-command positions, as seen in Figure 1. In both first-in-command and second-in-command positions, men held the clear majority of postings, as seen in Figure 3. 


\section{Cureus}

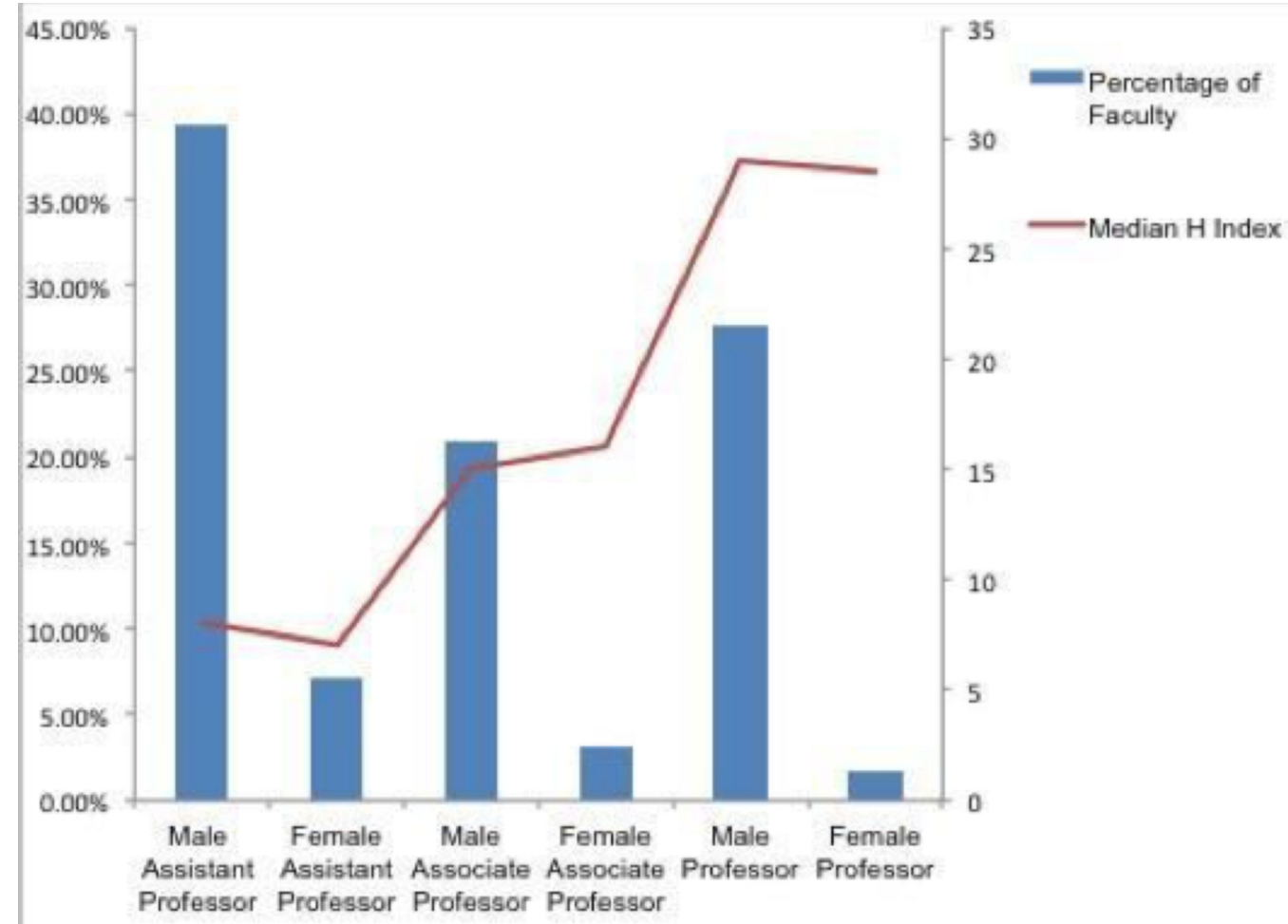

FIGURE 1: Percentage distribution of gender across leadership ranks

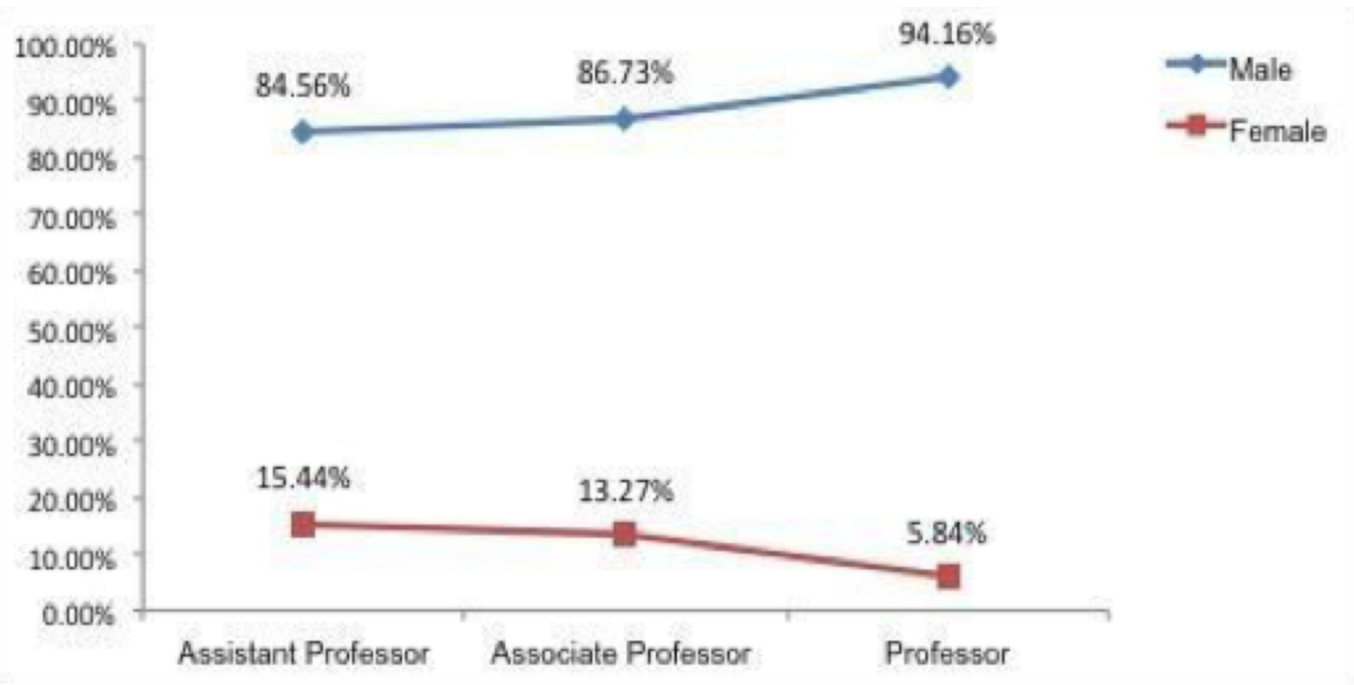

FIGURE 2: Percentage distribution of gender across academic strata 


\section{Cureus}

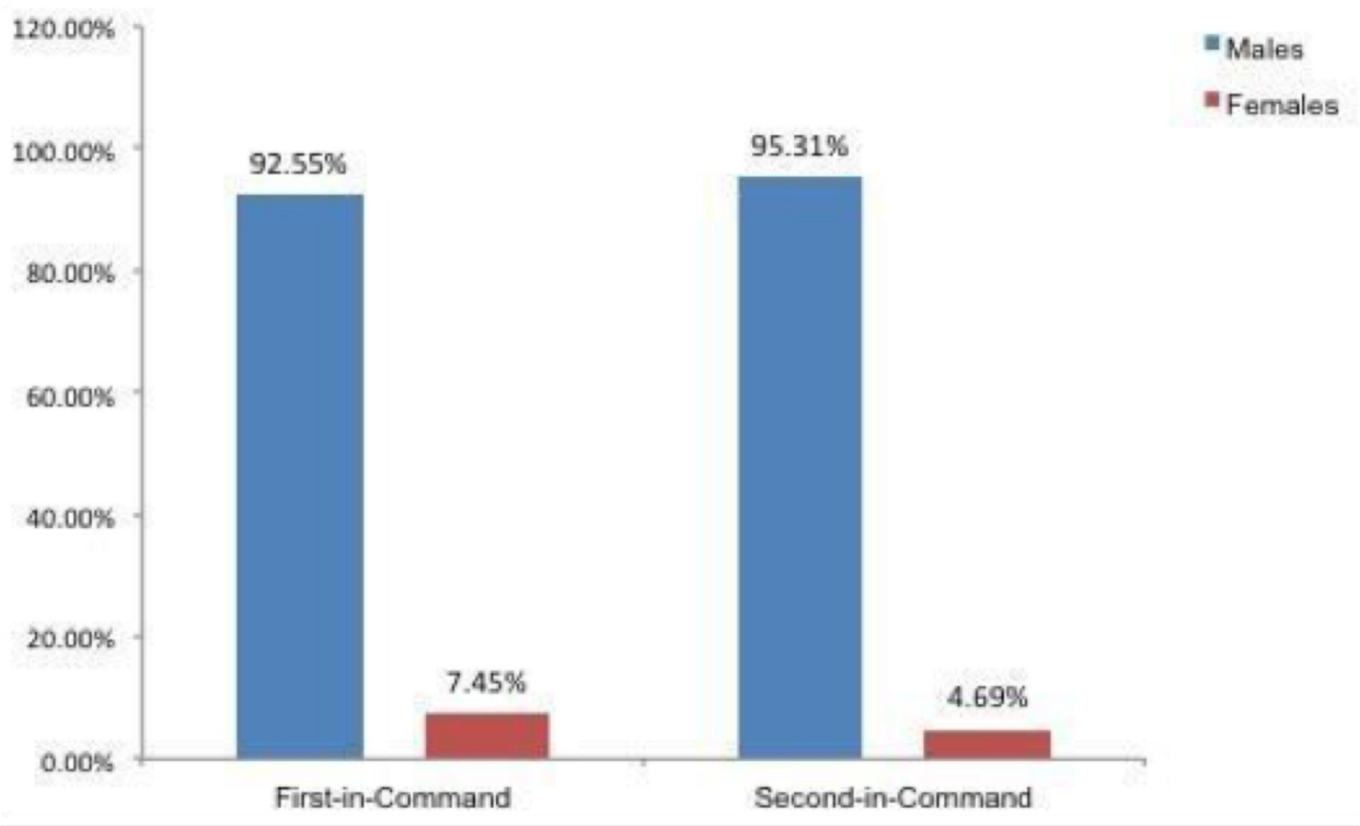

FIGURE 3: Percentage distribution of gender across academic strata

Applying the Kruskal-Wallis test, we saw that there was a significant difference in the h-index across different academic ranks (Chi-square $=481.56, \mathrm{DF}=2$, $\mathrm{p}$-value $\leqslant 0.001$ ). Looking at the $\mathrm{h}$ index across gender, we applied the Mann-Whitney $\mathrm{U}$ test and saw that there was a significant difference between male and female faculty $(\mathrm{z}=5.389, \mathrm{p}$-value $\leqslant 0.001)$. There was a significant difference between the total number of citations of papers of male and female faculty $(\mathrm{z}=4.736$. $\mathrm{p}$-value $\leqslant 0.001)$. There was a significant difference in the number of publications of male and female faculty $(\mathrm{z}=5.755$, $\mathrm{p}$-value $\leqslant 0.001)$. This significant difference was also noted even when we compared publications per year $(\mathrm{z}=3.8$, $\mathrm{p}$-value $\leqslant 0.001)$ and citations per years $(\mathrm{z}=2.966$, $\mathrm{p}$ value $\leqslant 0.001)$, as seen in Table 1 . The overall median h-index is $15(0-96)$. For all male faculty, the median h-index was 15 (0-96). For the female faculty, the median h-index was 10 (0-77). 


\section{Cureus}

\section{Variables}

Academic Rank

Male (median \& range)

H Index

Assistant Professor

Associate Professor

Professor

Publications

Assistant Professor
Associate Professor
Professor

Citations

Assistant Professor
Associate Professo
Professor

Years of Research

Assistant Professor
Associate Professo
Professor

Publications per year

Assistant Professor
Associate Professo
Professor

Citations per year

Assistant Professor
Associate Professor
Professor

Assistant Professor
$14(0-2017)$

$20(3-66)$

$30(2-66)$
$21(1-640)$
$18(1-364)$
$47(1-500)$
$42.5(3-164)$
$108.5(1-1109)$
$79(1-386)$

$1.5(0.09-22)$

$2.36(0.15-20.5)$

$2.67(0.15-12.43)$
$12(1-55)$

$16(2-40)$

$30(10-62)$

TABLE 1: Distribution of the $\mathrm{h}$-index, citations, publications, and years across gender

The index is on the $\mathrm{Y}$-axis and the regions are given on the $\mathrm{X}$-axis. We can see that some provinces in Canada and some states in the US have a much higher h-index than the median cut-off value based on this data. Given in Table 2 and Table 3 are the codes that identify the names of the regions and their respective median $\mathrm{h}$-index values. 


\section{Cureus}

\begin{tabular}{|c|c|c|c|c|c|c|}
\hline $\begin{array}{l}\text { Region } \\
\text { Code }\end{array}$ & State (USA) & $\begin{array}{l}\text { Median } \\
\mathrm{h} \text { - } \\
\text { index }\end{array}$ & $\begin{array}{l}\text { Higher than overall } \\
\text { median } h \text {-index of } \\
15\end{array}$ & $\begin{array}{l}\text { Median } h \text {-index } \\
\text { for male faculty }\end{array}$ & $\begin{array}{l}\text { Median h-index } \\
\text { for female } \\
\text { faculty }\end{array}$ & $\begin{array}{l}\text { Female h-index } \\
\text { higher than } \\
\text { median }\end{array}$ \\
\hline 1 & Alabama & 17 & $\sqrt{ }$ & 19 & 10.5 & \\
\hline 2 & Arizona & 7 & & 6.5 & 7 & \\
\hline 3 & Arkansas & 19 & $\sqrt{ }$ & 21 & 10 & \\
\hline 4 & California & 16 & $\sqrt{ }$ & 18.5 & 14 & \\
\hline 5 & Colorado & 12 & & 12 & & \\
\hline 6 & Columbia & 12 & & 12 & 10 & \\
\hline 7 & Connecticut & 12.5 & & 14.5 & 6 & \\
\hline 8 & Florida & 16 & $\sqrt{ }$ & 16.5 & 11 & \\
\hline 9 & Georgia & 9.5 & & 8.5 & 14 & \\
\hline 10 & Illinois & 24.5 & $\sqrt{ }$ & 24.5 & & \\
\hline 11 & Indiana & 13 & & 14 & 9 & \\
\hline 12 & lowa & 13 & & 15 & 11 & \\
\hline 13 & Kansas & 7 & & 8 & 5 & \\
\hline 14 & Kentucky & 22 & $\sqrt{ }$ & 23 & 7 & \\
\hline 15 & Louisiana & 24 & $\sqrt{ }$ & 24 & 29 & $\sqrt{ }$ \\
\hline 16 & Maryland & 29 & $\sqrt{ }$ & 30.5 & 19 & $\sqrt{ }$ \\
\hline 17 & Massachusetts & 8 & & 8 & & \\
\hline 18 & Michigan & 18 & $\sqrt{ }$ & 19 & 13 & \\
\hline 19 & Minnesota & 10 & & 11 & 3 & \\
\hline 20 & Mississippi & 11 & & 31.5 & 18 & $\sqrt{ }$ \\
\hline 21 & Missouri & 30 & $\sqrt{ }$ & 11 & 20 & $\sqrt{ }$ \\
\hline 22 & Nebraska & 17 & $\sqrt{ }$ & 15 & 10.5 & \\
\hline 23 & New Jersey & 13 & & 19 & 7 & \\
\hline 24 & New Mexico & 11 & & 22 & 7 & \\
\hline 25 & North Carolina & 21.5 & $\sqrt{ }$ & 22 & 8 & \\
\hline 26 & Ohio & 5.5 & & 5.5 & & \\
\hline 27 & Oklahoma & 15.5 & $\sqrt{ }$ & 15 & 20 & $\sqrt{ }$ \\
\hline 28 & Oregon & 10 & & 10 & $r$ & \\
\hline
\end{tabular}




\section{Cureus}

$\begin{array}{llllll}29 & \text { Pennsylvania } & 10 & & 12 & 6 \\ 30 & \text { Puerto Rico } & 19 & \sqrt{ } & 20.5 & 9.5 \\ 31 & \text { South Carolina } & 17 & \sqrt{ } & 19 & 16 \\ 32 & \text { Tennessee } & 7.5 & & 7.5 & 8.5 \\ 33 & \text { Texas } & 20 & \sqrt{ } & 22 & 19 \\ 34 & \text { Utah } & 22.5 & \sqrt{ } & 23.5 & 18 \\ 35 & \text { Vermont } & 19 & \sqrt{ } & 19 & \\ 36 & \text { Virginia } & 7 & & 8.5 & 3 \\ 37 & \text { Washington } & 14 & & 15 & 4.5 \\ 38 & \text { West Virginia } & 15 & & 15 & \\ 39 & \text { Wisconsin } & 25 & \sqrt{ } & 25 & 21\end{array}$

TABLE 2: Median h-index distribution across state areas

\begin{tabular}{|c|c|c|c|c|c|c|}
\hline $\begin{array}{l}\text { Region } \\
\text { Code }\end{array}$ & $\begin{array}{l}\text { Province } \\
\text { (Canada) }\end{array}$ & $\begin{array}{l}\text { Median } \\
\text { h-index }\end{array}$ & $\begin{array}{l}\text { Higher than overall } \\
\text { median } h \text {-index of } \\
15\end{array}$ & $\begin{array}{l}\text { Median } \mathrm{h} \text {-index } \\
\text { for male faculty }\end{array}$ & $\begin{array}{l}\text { Median h-index } \\
\text { for female } \\
\text { faculty }\end{array}$ & $\begin{array}{l}\text { Female } \mathrm{h} \text {-index } \\
\text { higher than } \\
\text { median }\end{array}$ \\
\hline 1 & Alberta & 22.5 & $\sqrt{ }$ & 23 & 14 & \\
\hline 2 & $\begin{array}{l}\text { British } \\
\text { Columbia }\end{array}$ & 9 & & 7.5 & 13 & \\
\hline 3 & Manitoba & 14 & & 15 & 6.5 & \\
\hline 4 & Quebec & 9 & & 17.5 & 7 & \\
\hline 5 & Nova Scotia & 13 & & 30 & 17 & $\sqrt{ }$ \\
\hline 6 & Ontario & 8.5 & & 10 & 0 & \\
\hline 7 & Saskatchewan & 6 & & 7 & 5.5 & \\
\hline
\end{tabular}

TABLE 3: Median h-index distribution across province areas

Data were tested for normality. Log transformation was done for the continuous variables of the h-index, citations, years, and number of publications, which were initially skewed in distribution. At the univariate level, simple linear regression was applied. We choose the pvalue of 0.25 for the univariate level, so as to enter the maximum number of variables in the model. Each variable was regressed independently with the h-index, their assumptions were checked, and their significance was reported. Gender was our primary exposure of interest. 
Variables that were significant on univariate regression were gender ( $p$-value $\leqslant 0.001$ ), publications ( $p$-value $\leqslant 0.001$ ), citations ( $p$-value $\leqslant 0.001$ ), years of active research ( $p$-value $\leqslant 0.001$ ), academic ranks ( $p$-value $\leqslant 0.001$ ), publications per year ( $p$-value $\leqslant 0.001$ ), and citations per year ( $p$-value $\leqslant 0.001)$. Leadership ranks ( $p$-value $=0.55$ ) was dropped from the model, as it was insignificant. Next, they were selected for inclusion into the multivariable linear regression analysis. We checked for multicollinearity between independent variables and were assessed using a correlation coefficient. Cramer's V test was used for one nominal and one ordinal variable, and the Spearman test was used for one continuous variable and one ordinal variable. A correlation of 0.8 was treated as the presence of multicollinearity. There was no multicollinearity seen. Main effects were identified using a stepwise selection strategy and based on the p-value, we decided to keep a variable in the model or remove it. Leadership ranks were brought forward again in the multivariable model but were again dismissed from the model ( $p$-value $=0.19$ ). The multivariable analysis supported the inclusion of gender, citations, publications, academic rank, and years of research in the preliminary model. The final step was to check for interaction. Interaction terms were created between each of the main effects in the model; there was significant interaction between academic ranks and publications ( $\mathrm{p}$-values = 0.06 and 0.08 ) and academic ranks and citations ( $\mathrm{p}$ values $=0.01$ and 0.71 ). We can deduce that the odds among the female faculty of having a higher $\mathrm{h}$-index are significantly lower $(\mathrm{OR}=0.65)$ than the male faculty, keeping all other variables constant.

The final model revealed $y(x)=\beta 0+\beta 1($ Gender $)+\beta 2$ (Publications $)+\beta 3$ (Citations $)+$ $\beta 41$ (Academic Rank- Associate Professor) $+\beta 42$ (Academic Rank- Professor) $+\beta 5$ (Years of research $)+\beta 6$ (Publications per year) $+\beta 7$ (Citations per year) $\beta 81$ (Academic Rank Associate Professor * Publications) + $\beta 82$ (Academic Rank Professor * Publications) + $\beta 91$ (Academic Rank Associate Professor * Citations) $+\beta 82$ (Academic Rank Professor * Citations).

This prediction equation accounted for major variability in the model as adjusted $\mathrm{R}$ square $=$ 0.82 , $F$ test was 1618.1 , and $p$-value was $\leqslant 0.001$. The remaining variability in the model may have been explained by variables such as full-time versus part-time employment, years of employment, and contract versus tenure positions. However, this was beyond the scope of our paper, as we used the data that was available on the Internet.

\section{Discussion}

From a historical perspective, there has been a female presence in neurosurgical-type practice dating as far back as the fifteenth century, when there are accounts of Turkish women performing solo surgical practice akin to pediatric neurosurgery [11]. In these records, women called Tabibes participated in the extraction of fetuses with hydrocephalus and macrocephaly from the womb [11]. In modern medicine, Diana Beck MD was the first female neurosurgeon. She was trained first as an apprentice under Hugh Cairns MD in 1939 at Radcliffe Infirmary in Oxford and then went on to become the first female neurosurgeon by accepting a position at Royal Free Hospital in 1943 [12]. Dr. Beck's academic pedigree includes a degree of displacement from Harvey Cushing, who is commonly revered as the "Father of Neurosurgery" and William Halstead, who is one of the "Founding Four” professors at John's Hopkins Hospital. In the twentieth century, women in neurosurgery have experienced exponential growth, beginning with pioneer, Ruth Kerr Jakoby MD, who is credited as being the first woman to hold an American Board of Neurological Surgery (ABNS) certification. During that same decade, 1960-1969, only one other woman joined the ranks of ABNS certification with Dr. Jakoby [12-13]. Since then, this number has grown significantly over the last 60 years, from five in the following decade (1970-1979), to 67 from 1990-1999, and now well over 200 ABNScertified female neurosurgeons $[12,14]$.

While the overall number of women in neurosurgery as compared to men holds steady from residency to academic appointments, we found an abrupt decrease in the number of women 
holding full professorships as compared to the assistant professor and associate professor titles. Among the 1,181 faculty members, men, by and large, outnumbered women (87.91\% vs $12.01 \%$, respectively). At $12 \%$, the overall number of women in academic neurosurgery in this data set matches that of women in other studies. For example, an analysis of a cohort of medical applicants matched to neurosurgical residency between 2000-2009 found females to constitute $12 \%$ of successful applicants [15]. When we break down the data set by academic appointment, women continue to represent just over $12 \%$ of neurosurgeons at the assistant and associate professor levels, accounting for $15.44 \%$ of assistant professors and $13.27 \%$ associate professors. Interestingly, at the full professor level, there is a significant drop in the proportion of women holding these positions (only 5.84\%). Likewise, there is also a significantly lower number of women holding leadership positions within their departments. Only $7.45 \%$ of women hold first-in-command positions and $4.69 \%$ hold second-in-command positions. Only two women have ever chaired academic neurosurgery departments [16]. As with many other medical subspecialties, the promotion of women to leadership positions has yet to catch up with the increase in the female population in neurosurgery as a whole. The reasons behind this have not yet been defined but are multifactorial.

There are two significant publications citing the importance of women in neurosurgery, with a call for reducing the gender bias within the specialty. One, published in 2008 by Benzil et al., examines the future of neurosurgery with a focus on the recruitment and retention of women within the field, stating that women are vital to the specialty and its growth [17]. The second, published in 2011 by Robert Spetzler MD, stresses the goal that "gender is less important than the overarching fact that we are all just Neurosurgeons" [18]. Studies such as the Benzil et al. 2008 study on the recruitment and retention of women in neurosurgery have identified several barriers hindering the entrance of women into the field of neurosurgery. These include, but may not be limited to, lifestyle concerns, scarcity of female mentorship, lack of up-to-date career programs, socio-cultural belief systems, discrimination, lack of encouragement in medical school, and early negative experiences [15,19-20]. While lifestyle is a major factor in career choice for medical students, the 80-hour week seems to have little effect on female medical students' decision to pursue surgery as a career. The effect of the 80-hour work week specific to neurosurgery has yet to be studied [21-23].

Nonetheless, many of the issues proposed in the 2008 white paper on the recruitment and retention of women in neurosurgery still hold true. The critical mass of $15 \%$, the percentage of female neurosurgeons, which would comprise an adequate population from which to derive female role models/mentors for aspiring young neurosurgeons, has yet to be reached. There is still a need for programs to expose medical students to female neurosurgeons, which may help to encourage female students to enter the field. Neumayer et al. noted that women who attend medical schools with higher proportions of female surgical faculty are more likely to enter surgical residency programs. To achieve this, females in leadership positions in the field of neurosurgery must also increase.

Although overall progress has been slow in recent years, there have been several major milestones. In 2016, Dawn R. Tartaglione DO became the first osteopathic neurosurgeon, and the third female, to be appointed as president of the American College of Osteopathic Surgeons. In April 2017, Shelly D. Timmons MD was the first female neurosurgeon to be named the president of the American Association of Neurological Surgeons (AANS). This represents an important symbolic change as the only major neurosurgical professional organization to name a female leader. Our study confirms the paucity of women in neurosurgery not only in overall numbers but increasingly so in higher academic positions and research productivity. Future studies could examine other potential variables such as marital status, the number of children, and the age of female neurosurgeons at various academic stages. 


\section{Conclusions}

While the overall number of women in neurosurgery as compared to men holds steady from residency to academic appointments, we found an abrupt decrease in the number of women holding full professorships as compared to the assistant professor and associate professor titles. Our study confirms the paucity of women in neurosurgery not only in overall numbers but increasingly so in higher academic positions and research productivity. This finding warrants further investigation and future studies could examine other potential variables such as marital status, the number of children, and the age of female neurosurgeons at various academic stages.

\section{Additional Information \\ Disclosures}

Human subjects: All authors have confirmed that this study did not involve human participants or tissue. Animal subjects: All authors have confirmed that this study did not involve animal subjects or tissue. Conflicts of interest: In compliance with the ICMJE uniform disclosure form, all authors declare the following: Payment/services info: All authors have declared that no financial support was received from any organization for the submitted work. Financial relationships: All authors have declared that they have no financial relationships at present or within the previous three years with any organizations that might have an interest in the submitted work. Other relationships: All authors have declared that there are no other relationships or activities that could appear to have influenced the submitted work.

\section{References}

1. Enrollment, graduates, and MD-PhD data . (2018). Accessed: January 02, 2018: https://www.aamc.org/data/facts/enrollmentgraduate/.

2. The state of women in academic medicine: the pipeline and pathways to leadership, 20152016. (2018). Accessed: January 02, 2018: https:/www.aamc.org/members/gwims/statistics/.

3. Number of female medical school enrollees reaches 10-year high . (2016). Accessed: December 12, 2017: https://news.aamc.org/press-releases/article/applicant-enrollment-2016/.

4. Qamar SR, Khurshid K, Jalal S, Bancroft L, Munk PL, Nicolaou S, Khosa F: Academic musculoskeletal radiology: influences for gender disparity. Skeletal Radiol. 2017, 47:381-387. 10.1007/s00256-017-2836-x

5. Ahmadi M, Khurshid K, Sanelli P, et al.: Influences for gender disparity in academic neuroradiology. AJNR Am J Neuroradiol. 2017, 39:18-23. 10.3174/ajnr.a5443

6. Pashkova AA, Svider PF, Chang CY, Diaz L, Eloy JA: Gender disparity among US anaesthesiologists: are women underrepresented in academic ranks and scholarly productivity?. Acta Anaesthesiol Scand. 2013, 57:1058-1064. 10.1111/aas.12141

7. Shah A, Jalal S, Khosa F: Influences for gender disparity in dermatology in North America . Int J Dermatol. 2018, 57:171-176. 10.1111/ijd.13875

8. Khurshid K, Shah S, Ahmadi M, Jalal S, Carlos R, Nicolaou S, Khosa F: Gender differences in the publication rate among breast imaging radiologists in the United States and Canada. Am J Roentgenol. 2018, 210 (1):2-7. 10.2214/ajr.17.18303

9. Physician specialty data report. Association of American Medical Colleges. (2016). Accessed: January 15, 2018: https://www.aamc.org/data/workforce/reports/492536/2018-physicianspecialty-data-report.html.

10. Women surgeons and the challenges of "having it all" . (2015). Accessed: January 23, 2018: https://gender.stanford.edu/news-publications/gender-news/women-surgeons-andchallenges-having-it-all.

11. Bademci G: First illustrations of female "Neurosurgeons" in the fifteenth century by Serefeddin Sabuncuoglu [Article in Spanish]. Neurocirugía. 2006, 17:162-165. 10.4321/s113014732006000200012

12. A WINS-win situation. (2012). Accessed: February 7, 2019: http://v1archives.aansneurosurgeon.org/210312/8/2057.

13. Women in neurosurgery (WINS) . (2017). Accessed: December 28, 2017: 
http://www.neurosurgerywins.org/doctor/dr-ruth-jakoby.

14. Women in neurosurgery: past, present and future . (2015). Accessed: February 7, 2019: https:/www.cns.org/publications/congress-quarterly/congress-quarterly-spring2015/women-neurosurgery-past-present.

15. Renfrow JJ, Rodriguez A, Liu A, et al.: Positive trends in neurosurgery enrollment and attrition: analysis of the 2000-2009 female neurosurgery resident cohort. J Neurosurg. 2016, 124:834-839. 10.3171/2015.3.jns142313

16. Abosch A, Rutka J: Women in neurosurgery: inequality redux . J Neurosurg. 2018, 129:277-281. 10.3171/2018.4.JNS172878

17. Benzil DL, Abosch A, Germano I, et al.: The future of neurosurgery: a white paper on the recruitment and retention of women in neurosurgery. J Neurosurg. 2008, 109:378-386. 10.3171/jns/2008/109/9/0378

18. Spetzler R: Progress of women in neurosurgery . Asian J Neurosurg. 2011, 6:6-12. 10.4103/1793-5482.85627

19. Woodrow SI, Gilmer-Hill H, Rutka JT: The neurosurgical workforce in North America: a critical review of gender issues. Neurosurgery. 2006, 59:749-758. 10.1227/01.neu.0000232671.44297.df

20. Riska E: Gender and medical careers. Maturitas. 2011, 68:264-267. 10.1016/j.maturitas.2010.09.010

21. Zarebczan B, Rajamanickam V, Lewis B, Leverson G, Sippel RS: The impact of the 80-hour work week on student interest in a surgical career. J Surg Res. 2011, 171:422-426. 10.1016/j.jss.2010.08.008

22. Etzkowitz H, Kemelgor C, Neuschatz M, Uzzi B: The paradox of critical mass for women in science. Athena Unbound. Elsevier, 1994. 51-54. 10.1017/cbo9780511541414.008

23. Neumayer L, Kaiser S, Anderson K, et al.: Perceptions of women medical students and their influence on career choice. Am J Surg. 2002, 183:146-150. 10.1016/S0002-9610(01)00863-7 